\title{
Synthesis and Characterization of Strontium Oxide Nano Particle by Sol-Gel Method
}

\author{
ALIMUDDIN $^{1 *}$ and MOHD RAFEEQ ${ }^{2}$ \\ 1'Department of Chemistry, School of Sciences, Maulana Azad National Urdu University, \\ Gachibowli, Hyderabad-500032, India. \\ 2Department of CS\&IT, School of Technology, Maulana Azad National Urdu University, \\ Gachibowli, Hyderabad-500032, India. \\ ${ }^{*}$ Corresponding author E-mail: khanalim192@gmail.com \\ http://dx.doi.org/10.13005/ojc/370124
}

(Received: November 27, 2020; Accepted: January 05, 2021)

\begin{abstract}
Synthesis of strontium oxide nanoparticles was carried out by sol-gel method using strontium nitrate and sodium hydroxide at room temperature which is very simple and cost effective. The characterization of strontium oxide nanoparticles was done using X-ray diffraction, scanning electron microscopy (SEM) and Fourier transform infra-red (FTIR). X-ray diffraction pattern indicates that the nanoparticles are crystalline in nature. The crystalline size of strontium oxide nanoparticle was calculated by Debye-Scherrer formula. The crystalline sizes are about $80 \mathrm{~nm}$. The morphology of nanoparticles was observed and investigated using SEM. The material at room temperature, calcined at $200^{\circ} \mathrm{C}, 400^{\circ} \mathrm{C}$ and $600^{\circ} \mathrm{C}$ respectively shows pseudo spherical shape, cubic form and finally it becomes cylindrical this shows that there is a agglomeration with increase in temperature. FTIR spectrum of strontium oxide shows the peak at $854.64 \mathrm{~cm}^{-1}$ which is due to $\mathrm{Sr}-\mathrm{O}$ bond.
\end{abstract}

Keywords: Strontium oxide, Nanoparticle, XRD, SEM, FTIR.

\section{INTRODUCTION}

Strontium oxide nanoparticle had received great attention in basic and applied research for fabricating the devices because of its unique properties ${ }^{1-5}$.

Strontium oxide nanoparticle is used to design the devices for dye-sensitized solar cells, electrodes for lithium ion battery, super capacitors, transistors, doped semiconductors, solar cells and gas sensors because of its morphology $\mathrm{y}^{6-10}$.

Growth of nanoparticles are depends on many factors such as viscosity, temperature and concentration of the medium. The growth of nanoparticle changed in the dependence on method of preparation of nanoparticle. The methods of synthesis of nonmaterial solids had been improved due to materials, scientist and engineers ${ }^{11-14}$. Nanoparticles synthesis with unique properties is a new area of research which is a great importance. There are various methods to synthesize these materials in liquid phase such as hydrothermal ${ }^{15-18}$, sol-gel ${ }^{19-22}$, micro emulsion and microbial processes, out of these methods sol gel is a simple and cost effective method ${ }^{23}$. Due to different

This is an Open Access article licensed under a Creative Commons license: Attribution 4.0 International (CC- BY). Published by Oriental Scientific Publishing Company @ 2018 
physical and chemical properties such as higher damping property, mechanical stability and good thermal conductivity nanoparticles have received a great attention in last few years ${ }^{24}$. Nanomaterials are known for many novel properties due to their nanometer size; many novel applications are already known from these novel properties.

The synthesis of strontium oxide nanoparticles was carried out by biometric method using ocimum sanctum leaf extract ${ }^{6}$ and by wet process $^{10}$.

Therefore, the aim of this paper is to synthesize strontium oxide nanoparticle and investigate there morphology and uses in various field which is cost effective method as compared to other methods.

\section{MATERIALS AND METHODS}

\section{Reagents and chemicals}

Strontium nitrate were obtained by E. Merck \& Co.(India). All the other reagents and chemicals applied here was of AnalaR grade.

\section{Instrumentation}

An Elico $\mathrm{pH}$ meter is used for measuring the $\mathrm{pH}$ level. Whereas for heating these samples on varying temperatures, a muffle furnace was used. FTIR spectra are done using an FTIR Nicolet 50X spectrophotometer model in the region of 400-4000 $\mathrm{cm}^{-1}$ as $\mathrm{KBr}$ pallets. CuK $\alpha$ radiations were applied in diffractometer PW1820 for recording powder $\mathrm{X}$-ray diffraction. The morphological studies were accomplished by SEM.

\section{Synthesis}

$0.2 \mathrm{M}$ strontium nitrate solution was taken in a beaker and $0.5 \mathrm{M} \mathrm{NaOH}$ solution was added drop wise, after few minutes the white precipitate of strontium hydroxide was appeared in a beaker. The $\mathrm{pH}$ of the solution was measured 12.6 by Elico $\mathrm{pH}$ meter. The precipitate was washed with methyl alcohol two to three times in order to remove ionic impurities. The product was centrifuged for $5 \mathrm{~min}$ at $5000 \mathrm{rpm} / \mathrm{min}$ and dried at room temperature.

\section{RESULT AND DISCUSSION}

X-ray diffraction pattern shows crystalline nature of nanoparticle. Diffraction peaks matches with the database (JCPDS file \#6-520) which corresponds to $\mathrm{Sr}(\mathrm{OH})_{2}$ with cubic structure. The Debye-Scherrer equation $D=0.94 \lambda / \beta \cos \theta^{25}$ was used to calculate the crystalline size, where $\beta$ is the full width at half maximum of peak. $\lambda$ represent the $X$-ray wavelength and $\theta$ referred as Bragg diffraction angle. The crystalline size is about $80 \mathrm{~nm}$. The X-ray diffraction pattern is shown in Figure 1.

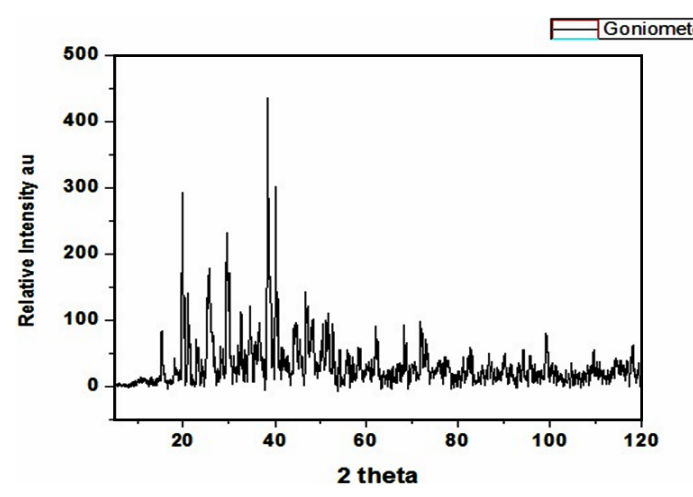

Fig. 1. Powder X-ray diffraction pattern of strontium oxide nanoparticles

Figure 2(a) shows SEM image of strontium oxide nanoparticle at room temperature which show pseudo spherical shape. As the temperature increases upto $400^{\circ} \mathrm{C}$ it starts agglomeration and the shape becomes cubic Fig. 2(b\&c). Finally it becomes cylindrical Fig. 2(d) on further increase of temperature upto $600^{\circ} \mathrm{C}$. This shows that there is an agglomeration with increase in temperature.

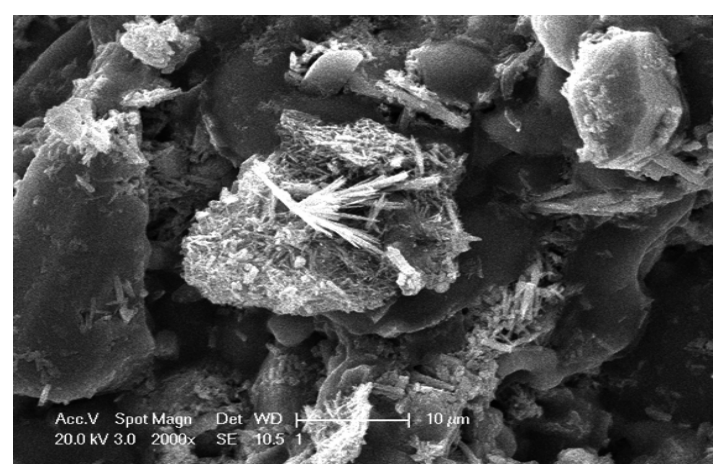

Fig. 2(a). SEM at room temperature of strontium oxide nanoparticles

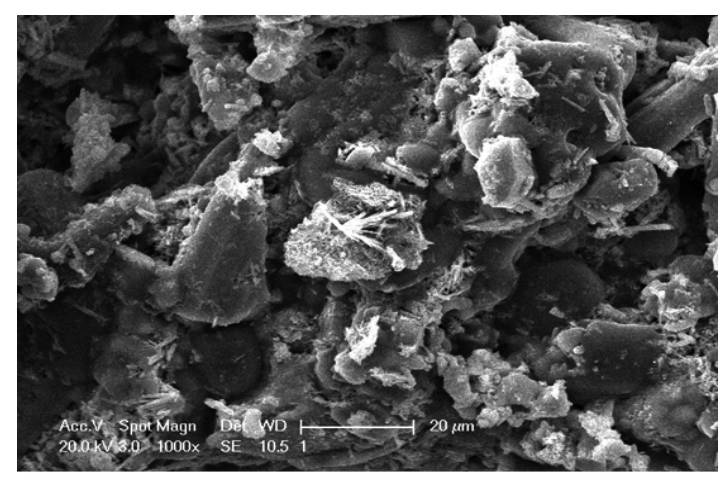

Fig. 2 (b). SEM at $200^{\circ} \mathrm{C}$ of strontium oxide nanoparticles 


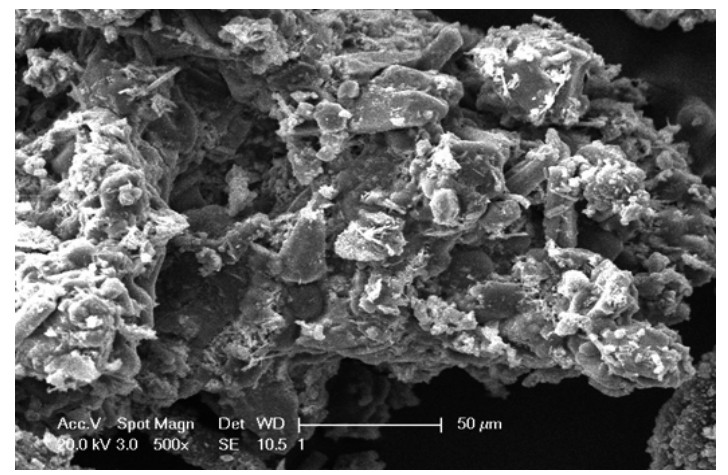

Fig. 2(c). SEM at $400^{\circ} \mathrm{C}$ of strontium oxide nanoparticles

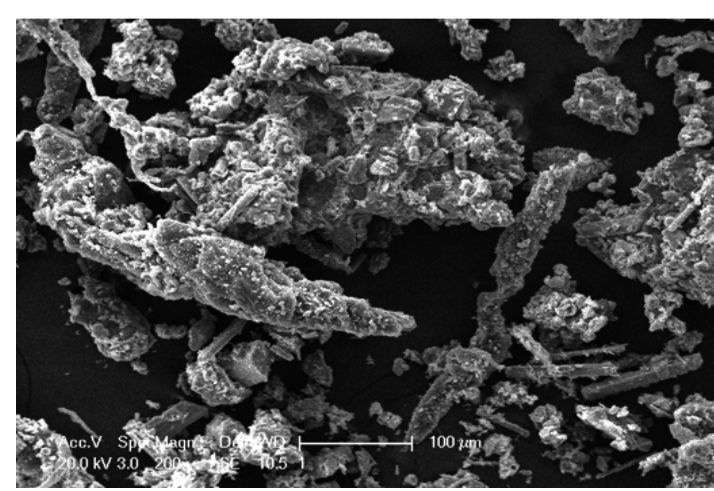

Fig. 2(d). SEM at $600^{\circ} \mathrm{C}$ of strontium oxide nanoparticles

FTIR spectrum of strontium oxide nanoparticle Fig. 3 shows the peak at $854.64 \mathrm{~cm}^{-1}$ which is due to $\mathrm{Sr}-\mathrm{O}$ bond $^{26}$. A sharp peak at 1339.75 $\mathrm{cm}^{-1}, 1788.45 \mathrm{~cm}^{-1}, 2425.97 \mathrm{~cm}^{-1}$ and, $2917.07 \mathrm{~cm}^{-1}$ was because of $\mathrm{H}-\mathrm{O}-\mathrm{H}$ bending ${ }^{6,27}$. The peak at $3000-3600 \mathrm{~cm}^{-1}$ region represents the $-\mathrm{OH}$ group and interstitial water molecule ${ }^{28}$

\section{CONCLUSION}

Strontium oxide nanoparticles were

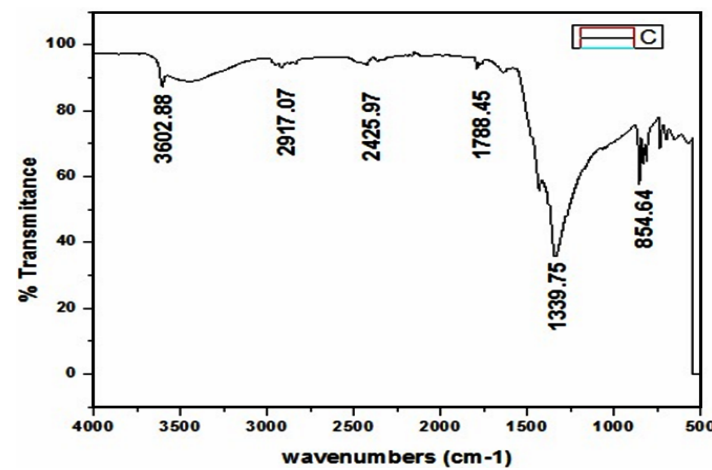

Fig. 3. FTIR spectrum of strontium oxide nanoparticles

synthesised using the sol-gel method. Material heated at $200^{\circ} \mathrm{C}, 400^{\circ} \mathrm{C}$ and $600^{\circ} \mathrm{C}$. Characterization of SrO nanoparticles was done using X-ray diffraction, SEM and Fourier transform infra-red (FTIR). X-ray diffraction pattern indicates that nanoparticles are of a crystalline nature. The SrO nanoparticle crystalline size was calculated using the Debye-Scherrer formula. Around 80nm is the crystalline size. The material can be used to design lithium ion battery electrode devices, transistors, doped semiconductors, solar cells, and gas sensors.

\section{ACKNOWLEDGEMENT}

The authors are thankful to Dean School of Sciences and Dean School of Technology for providing research facilities.

\section{Conflicts of interest}

The authors declare that there is no conflict of interest regarding the publication of this article.

\section{REFERENCES}

1. José-Yacamán M, Mehl R,; Medalist $A$. Metallurgical and Material Transactions A., 1998, 29, 713-725.

2. Hu, C. C.; Tsou T. W. Journal of Power Sources., 2003, 115, 179-186.

3. Miura, N.; Oonishi, S.; Prasad, K.R. Electrochemical and Solid-State Letters., 2004, 7(8), A247-A249.

4. Hepel, M. Journal of Electrochemical Society., 1998, 145, 124-133.

5. Mandal, B.M. Bulletin Material Science., 1998, 21, 161-165.
6. Apsana, G.; George, P. P.; Devanna, N., Yuvasravana, R. Asian Journal of Pharmaceutical and Clinical Research., 2018, 11(1), 384-389.

7. Schmid, H.K.; Aslan, M.; Assmann, S.; Nab, R. Journal of Europian Ceramic Society., 1998, 18, 39-49.

8. Yang, Y.; Chen, H.; Zhao, B.; BaO, X. Journal of Crystal Growth., 2004, 263, 447-453.

9. Prasad, K.R.; Miura, N.; Electrochemical Communication., 2004, 6, 849-852.

10. Athar, T. Materials Focus., 2013, 2, 450-453. 
11. Pal, S.L; Jana, U.; Manna, P.K., Mohanta, G.P.; Manavalan, R. J. Applied Pharamaceutical Science., 2011, 1(6), 228-234.

12. Hasany, S.F.; Ahmad, I.; Ranjan, J.; Rehman, A. Nanoscience and Nanotechnology., 2012, 2(6), 148-158.

13. Lue, J.T. Encyclopedia of nanoscience and nanotechnology., 2007, 10, 1-46.

14. Rajput, N. International Journal of Advances in Engineering and Technology., 2015, 7(4), 1806-1811.

15. Vernardou, D.; Kazas, A.; Apostolopoulou, M.; Katsarakis, N.; Koudoumas, E. Journal of Electronic Materials., 2017, 46(4), 2232-2240.

16. Vernardou, D.; Louloudakis, D.; Spanakis, E.; Katsarakis, N. New Journal of Chemistry. 2014, 38, 1959-1964.

17. Vernardou, D.; Vasilopoulos, K. C.; Kenanakis, G. Applied Physics A., 2017, 123, 623-629.

18. Trapatseli, M.; Vernardou, D.; Tzanetakis, P.; Spanakis, E. ACS applied materials \& interfaces., 2011, 3, 2726-2731.

19. Mallahi, M.; Shokuhfar, A.; Vaezi, M. R.;
Esmaeilirad, A.; Mazinani, V. American J. of Engineering Research., 2014, 3(4), 162-165.

20. Tang, Q.; Zhub, H.; Chenb, C.; Wang, Y.; Zhu, Z.; Wu, J. Materials Research., 2017, 20(5), 1340-1344.

21. Brintha, S.R.; Ajitha, M. IOSR Journal of Applied Chemistry., 2015, 8(11), 66-72.

22. Hasnidawani, J.N.; Azlina, H.N. ; Norita, H.; Bonnia, N.N.; Ratim, S.; Ali, E.S. Procedia Chemistry., 2016, 19, 211-216.

23. Hedayati, K. J of Nanostruc., 2015, 5, 395-401.

24. Wahab, R.; Ansari, S.G.; Dar, M.A.; Kim, Y.S.; Shin, H.S. Materials Science Forum., 2007, 558-559, 983-986.

25. Hedayati, K.; Nabiyouni, G. Applied Physics A., 2014, 116, 1605-1612.

26. Bindhani, B. K.; Panigrahi, A. K. J. of Nanomedicine \& Nanotechnology., 2015, S6, 008.

27. Nabi, S. A.; Alimuddin, Islam, A. Journal of Hazardous Materials., 2009, 172(1), 202-207.

28. Smith, B. Infrared Spectral Interpretation: A Systematic Approach. CRC Press, Boca Raton., 1999. 